\title{
STRESS-STRAIN STATE OF CURVED LAMINATED WOODEN ELEMENTS DURING PRODUCTION
}

\author{
Alexander Schmidt \\ Saint Petersburg State University of Architecture and Civil Engineering \\ Vtoraja Krasnoarmeyskaya st., 4, Saint Petersburg, Russia \\ E-mail: shmidt.a.b@lan.spbgasu.ru
}

\begin{abstract}
Introduction: The stress-strain state (SSS) of curved laminated wooden elements may differ significantly from the SSS of straight laminated wooden elements, not only in terms of the curvature but also in terms of production specifics and operational load. A curved element is produced by bending wooden planks (lamellae) and gluing them together. In the process, the structure is subjected to initial internal stresses, as the lamellae tend to straighten out again. After production is complete, the element experiences unequal initial internal stresses, which alters its strength properties in different directions in relation to the timber fibers. At a later point, this is going to contribute to the stresses that the structure experiences under external pressure. The Russian and foreign regulations (SP, EuroCode 5, DIN) do not pay sufficient attention to this fact, which has merited this study. Methods: For the aforementioned purpose, we review a mathematical model of the SSS emergence in curved laminated wooden elements. We roughly divide the process into two stages: stage 1 involves bending separate lamellae, gluing them together, and pressing them down; stage 2 involves pressing out the laminated package. This results in prestress, which is a combination of tangential, radial, and shear stresses. Results: Our study results in a visual representation of the total prestress during stages 1 and 2 . Such a representation allows for predicting stresses in curved laminated wooden structures under alternating operational loads. Discussion: We highlight the impact of the relaxation of initial stresses, which requires further study. Depending on the direction and amount of operational load, the curved laminated section of a structure may "attempt" to straighten out (i.e. with a decrease in curvature), or may curve even further. This is not properly reflected in the guidelines for wooden structures' design and needs to be examined further.
\end{abstract}

\section{Keywords}

Curved laminated wooden element, production of curved wooden structures, initial prestress, combination of initial prestress and operational stresses.

\section{Introduction}

The stress-strain state (SSS) of straight laminated wooden structures (LWS) differs from that of curved LWS: the reason is that the latter experience internal stresses during production, as the laminated curves attempt to straighten out. After production, these stresses generate a complex initial stress state, complemented by the stress state caused by external loads, which occur during operation and may vary both in terms of the amount and the direction in which the different sections of the curved laminated structure are affected.

There have been a number of studies on the subject (Gordon, 1973; Serov et al., 2011), but they have been applied, both in theory and experimental practice, exclusively to the cornice joints of hockeystick type frames, which are invariably subjected to tension along the timber fibers within the outer radius and to compression along the timber fibers within the inner (smaller) radius. The studies do not look at radial compression, as it never results in destruction and always has significant reserves. The results of these studies are still applied to the
Russian guidelines on wooden structures' design (SP 64.13330.2017).

However, it should be noted that when the curved sections of a curved laminated structure bear a load that causes compression with a bend, they start experiencing a "straightening effect". Under such conditions, even the smallest curvature of the laminated section may significantly affect the stress, which is not considered by the wooden structures' design guidelines. A straightening force always results in tensile radial stresses across the timber fibers. Our own research (Schmidt, 1980) provides experimental proof that, when thus compressed, an element with a large curvature gets destroyed under the impact of tensile radial stresses. However, we did not conduct any further studies on the subject. Nonetheless, the above applies not just to bent elements (such as curved laminated beams) but specifically to compressed bent elements (depressed pointed arches, frames, etc.) that may experience a straightening force. In summary, the prestress generated during the production of curved laminated wooden structures must be inspected in more detail. 


\section{Methods}

For convenience, we shall divide the process of curved laminated structures' production into two stages: stage 1, when each of the lamellae gets coated in glue and bent along the required angle, and all lamellae are subsequently pressed together; and stage 2, when the glue dries and the structure relaxes.

The effort applied to bending each specific lamella in the package during stage 1 converts into elastic deformation energy that affects the entire curved laminated package at stage 2. As a result, the stress state of the finished curved laminated element equals the sum of the elastic processes that affect it during the first and second stages. The respective prestress has two mutually perpendicular directions: the radial (along the radius and across the timber fibers) and tangential (at a tangent to the arcs and along the bent timber fibers). With this in mind, we can write down the following generalized equation for the radial $\left(\sigma_{r}^{i n i t}\right)$, tangential $\left(\sigma_{\theta}^{\text {init }}\right)$, and shear $\left(\tau_{\theta r}^{\text {init }}\right)$ prestress:

$$
\left\{\begin{array}{l}
\sigma_{r}^{i n i t}=\sigma_{r}^{(1)}+\sigma_{r}^{(2)} \\
\sigma_{\theta}^{i n i t}=\sigma_{\theta}^{(1)}+\sigma_{\theta}^{(2)} \\
\tau_{\theta r}^{i n i t}=\ldots \ldots . .+\tau_{\theta \rho}^{(2)}
\end{array}\right\}
$$

Here, $\sigma_{r}$ and $\sigma_{\theta}$ stand for normal stresses, $\tau_{\theta r}$ stands for shear stresses, and (1) and (2) superscripts stand for the production stages.

We should note that during stage 1, there are no shear stresses either in separate layers or between them, while the radial $\sigma_{r}^{(1)}$ and tangential $\sigma_{\theta}^{(1)}$ stresses are mutually perpendicular in relation to the lamellae axis curves. Importantly, radial stresses at stage 1 are always compressive.

Let us now have a more in-depth look at the stress at stage 1.

Let us assume that each lamella bends strictly along the circular arc with a radius of $\rho_{i}$. A circular deformation of this kind can occur when the layer is experiencing pure bending. Therefore, we can conclude that:

$$
\frac{1}{\rho_{i}}=\frac{M_{i}}{E_{i} \cdot J_{i}},
$$

where $\rho_{i}$ is the mean curvature radius, while $M_{i}$ , $J_{i}$, and $E_{i}$ are the bending moment, the second area moment, and the modulus of elasticity in layer $i$, respectively.

We must point out that, if the beam axis has a circular outline, equation (2) shall remain true even for larger bending radii. In this case, calculations require a non-linear dependency between the strain parameters and the displacement components; integrating precise equations will yield a circle equation for the deformed beam axis (Filin, 1978), or for curves with a small radius.

When experiencing pure bending, no layers have shear stresses. There are radial $\sigma_{r}^{(1)}$ and tangential $\sigma_{\theta}^{(1)}$ stresses, however; these types of stress end up being principal stresses (axisymmetric problem).

Let us assume that a package consists of identical layers, i.e. $\delta_{i}=\delta, E_{i}=E$ and $J_{i}=J$. Then, for layer $i$, we find the data described in Figure 1 .

$$
M_{i}=\frac{E \cdot J}{\rho_{i}} \quad, \quad \sigma_{\theta i}^{(1)}=\frac{M_{i} \cdot y}{J}=\frac{E \cdot y}{\rho_{i}} .
$$

Having accepted that $y=\frac{\delta}{2}$ and specified $\beta_{i}=\frac{\rho_{i}}{\delta}$, we can find the values of the boundary tangential (or normal to the section) stresses along the edge of layer i during the first stage:

$$
\sigma_{\theta i}^{(1)}=\frac{E}{2 \beta_{i}} .
$$

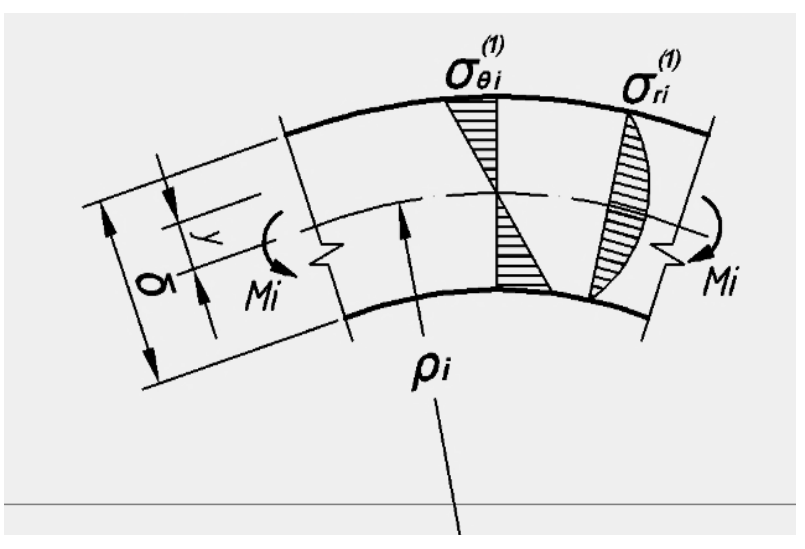

Figure 1. On finding the normal (tangential) and radial stresses in the $i^{\text {th }}$ curved layer

Our next step is to find the value of the maximum radial compressive stresses in layer $i$ at the first stage $\sigma_{r i}^{(1)}$, based on the layer's equilibrium equation (Figs. 1 and 2).

$$
\begin{gathered}
2 \int_{F} \sigma_{\theta i}^{(1)} d F \cdot \sin (d \gamma)=2 b \cdot \sin (d \gamma) \frac{E}{\rho_{i}} \int_{\alpha}^{\delta / 2} y \cdot d y= \\
=\sigma_{r i}^{(1)} b \cdot r_{i} \cdot 2 d \gamma .
\end{gathered}
$$

As the $d \gamma$ value is fairly small, we shall adopt the following ratio: $\frac{\sin (d \gamma)}{d \gamma} 1$.

Then

$$
\sigma_{r i}^{(1)}=\frac{E}{\rho_{i} \cdot r_{i} \cdot b} \cdot b \int_{\alpha}^{\delta / 2} y \cdot d y \text {. }
$$

It is obvious that $b \int_{\alpha}^{\delta / 2} y \cdot d y=S^{\text {trunc }}$ is the static moment of the section's truncated segment.

For a slightly curved beam $(\beta>20)$, like layer i $\left(\beta_{i} \geq 200\right)$ (Schmidt, 1980), it is feasible to assume that the point of maximum radial stresses is the central point within the wood $(y=0)$. Then $S^{\text {trunc }}=\frac{b \cdot \delta^{2}}{8}$. Bearing in mind that when $y=0$, 


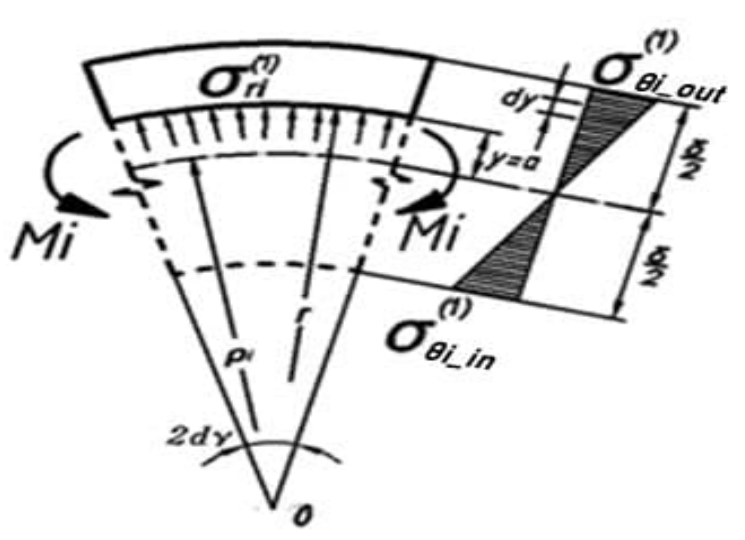

Figure 2. On determining the radial stresses in the $I_{\text {th }}$ layer

$r_{i}=\rho_{i}$ and $\beta_{i}=\frac{\rho_{i}}{\delta}$, we can derive the final values of the radial compressive stresses across the timber fibers:

$$
\max \sigma_{r i}^{(1)}=\frac{E}{8 \cdot \beta_{i}^{2}} .
$$

For simplicity, we shall hereinafter refer to as $\max \sigma_{r i}^{(1)}$ as $\sigma_{r i}^{(1)}$.

The straight layers, which get curved before the gluing process, shift in relation to one another within the boundaries of the curved section's central angle, by $\Delta l_{i}$ (Fig. 3). Notably, this shift decreases from the bottom layer $\Delta l$ towards the topmost layer $\Delta l_{n}$, since it only affects the curved section and is in reverse proportion to the curvature radius.

While in this state, the layers are pressed together; the impact of the press (after pressingout) has almost no effect on the SSS of the curved laminated layers' package.

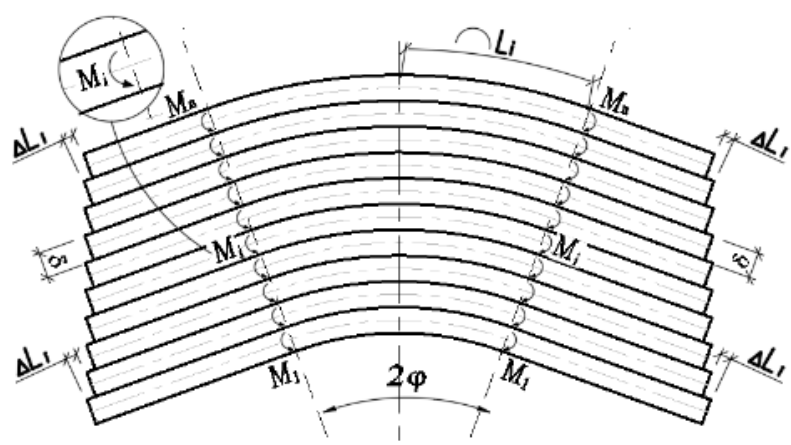

Figure 3. Deformed state at production stage 1

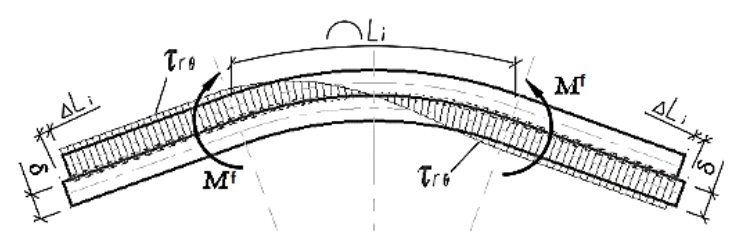

Figure 4. Distribution of shear stresses in the glue seams during stage 2 (package pressing-out)
We shall now move on to the stress at stage 2 , when the glue dries and the curved laminated element is pressed out. The package pressing-out process takes approximately 24 hours to complete. During this period, the glue gains around $80 \%$ of its strength and undergoes little deformation, preventing the lamellae from splitting and shifting in relation to one another, despite the force that compels the layers to straighten out.

Aside from the stresses that were generated at stage $1\left(\sigma_{\theta i}^{(1)}\right.$ and $\left.\sigma_{r i}^{(1)}\right)$, those lamellae layers that undergo "pure bending" also begin to experience shear stresses $\tau_{\theta r}^{(2)}$ at stage 2. The stresses occur in the seams between the layers and prevent them from shifting and straightening out (Fig. 4).

We shall determine the shear stresses (Fig. 4) by examining the relative shear strains in the seams, which equal the ratio between $\Delta \mathrm{li}$ and the length of the corresponding curved section of each lamella li. Then the shifts in relation to the initial layer, which used to be straight before the bending, will equal $\varepsilon_{i}=\frac{\Delta l_{i}}{l_{i}}$ define the maxir glue seams as follows:

$$
\tau_{\theta r i}=G \cdot \varepsilon_{i}
$$

where $G$ is the shear modulus of the hardened glue seam, which is usually taken equal to the shear modulus of the timber along the fibers.

Therefore, now that we have established that the physical and mechanical properties of the glue seam are similar to those of timber, we can assume that, once the glue hardens, this will result in a single and solid anisotropic body with a uniform structure, experiencing a complex stress-strain state (in essence, a prestress state).

The internal energy of the curved beam layers that are deformed by bending feeds the compulsion to undo the bend. We shall replace the cumulative action of all the bending moments $M_{i}$ that affected each layer previously with a static equivalent . In this case, pressing out the package is going to equal subjecting a curved beam, glued together from curved wooden lamellae, to a certain fictitious bending moment $M^{f}$, which equals $M$ but has the opposite direction (Fig. 5):

$$
M^{f}=\sum_{i=1}^{n} M_{i}=\sum_{i=1}^{n} \frac{E J_{0}}{\rho_{i}}=E \frac{b \cdot \delta^{2}}{12} \ln \left(1+\frac{n}{\beta_{1}}\right),
$$

where $b$ is the width of the plank package, $n$ is the number of planks (lamellae) in the package.

It is evident that, when subjected to $M^{f}$, the curved laminated element attempts to unbend (straighten out). In order to properly define the resulting stresses, we can use a dependency for assessing the properties of an anisotropic beam with a large curvature under pure bending conditions 


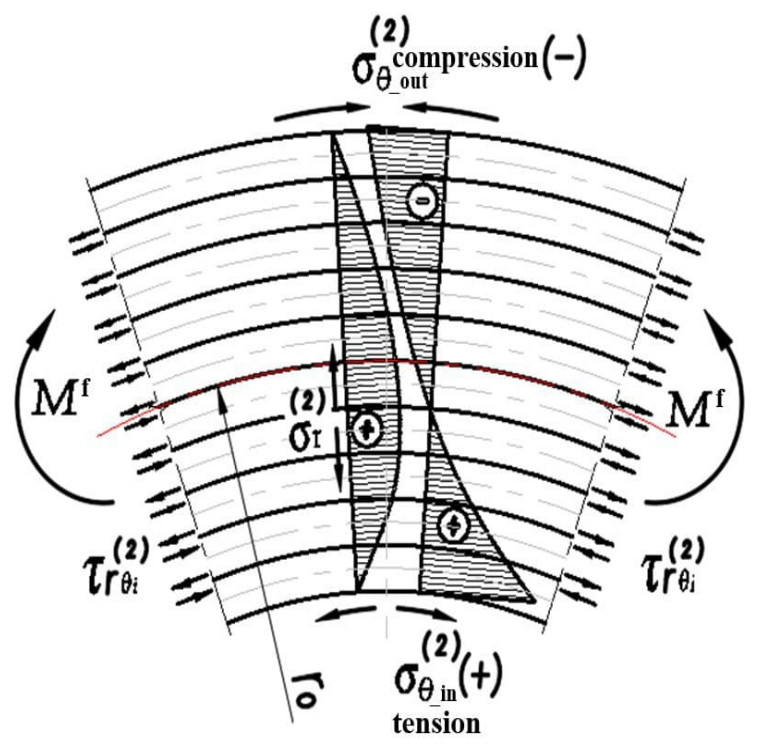

Figure 5. Stress state of the curved laminated beam during stage 2 (pressing out the glued package)

(Lekhnitsky, 1977; Schmidt, 1980). Specifically, we can use the known pure bending equations (American Wood Council, 2015; Foschi, 1971) for the boundary tangential stresses along the inner edge $\sigma_{\theta_{-} \text {in }}^{(2)}$ and along the outer edge $\sigma_{\theta_{-} \text {out }}^{(2)}$, as well as for the maximum radial stresses $\sigma_{r}^{(2)}$ :

$$
\begin{array}{cc}
\sigma_{\theta_{-} \text {in }}^{(2)}=\frac{M^{f}}{W}\left(1+\frac{1}{2 \beta}\right) \quad, \quad \sigma_{\theta_{-} \text {out }}^{(2)}=\frac{M^{f}}{W}\left(1-\frac{1}{6 \beta}\right), \\
\sigma_{r}^{(2)}=\frac{M^{f}}{W} \frac{1}{4 \beta}, & \tau_{\theta r}^{(2)}=G \cdot \varepsilon_{i},
\end{array}
$$

where $\quad \beta=\frac{r_{a v}}{h}=\frac{\beta_{1}}{n}+\frac{(n-1)}{2 n}$ is the relative curvature radius for the entire element.
We must stress that in this instance, unlike in Regulations SP 64.13330.2017 (Ministry of Construction, Housing and Utilities of the Russian Federation, 2017), it would be preferable to use alternative terms for the curved beam edges: "inner vs outer" rather than "upper vs lower", as in some modern structures, the curved sections can be positioned with their inner (concave) part at the top and outer (convex) part at the bottom. In other words, the inner edge is the edge closest to the center.

By substituting (3), (4), (5), (6) and (7) in equation (1), we find the initial prestress experienced by a curved laminated wooden element, specifically the prestress for boundary tangential stresses, shear stresses along the glue seam, and maximum radial stresses in each layer:

$$
\left.\begin{array}{l}
\left\{\begin{array}{l}
\sigma_{r}^{\text {init }}=-\frac{E}{8 \beta_{i}^{2}}+\frac{M^{f}}{W} \frac{1}{4 \beta} \\
\sigma_{\theta_{-}^{i n i}}^{\text {init }}=-\frac{E}{2 \beta_{1}}+\frac{M^{f}}{W}\left(1+\frac{1}{2 \beta}\right) \Rightarrow \\
\tau_{\theta r}^{\text {init }}=G \cdot \varepsilon_{i}
\end{array}\right. \\
\Rightarrow \sigma_{\theta_{-}^{\text {out }}}^{\text {init }}=\frac{E}{2 \beta_{1}}-\frac{M^{f}}{W}\left(1-\frac{1}{6 \beta}\right)
\end{array}\right\}
$$

Figure 6 illustrates the general process of hypothetical graphic cumulation of the curved element's stress during both stages, given that the number of layers (lamellae) $n=10$. Here, the stress diagrams for stage 1 and stage 2 are comparable in scale to the extent of the stresses, which affirms the existence of the resulting compression (-) along the inner edge fibers, tension $(+)$ along the outer edge fibers, and tension $(+)$ across the fibers at the center throughout the section height.
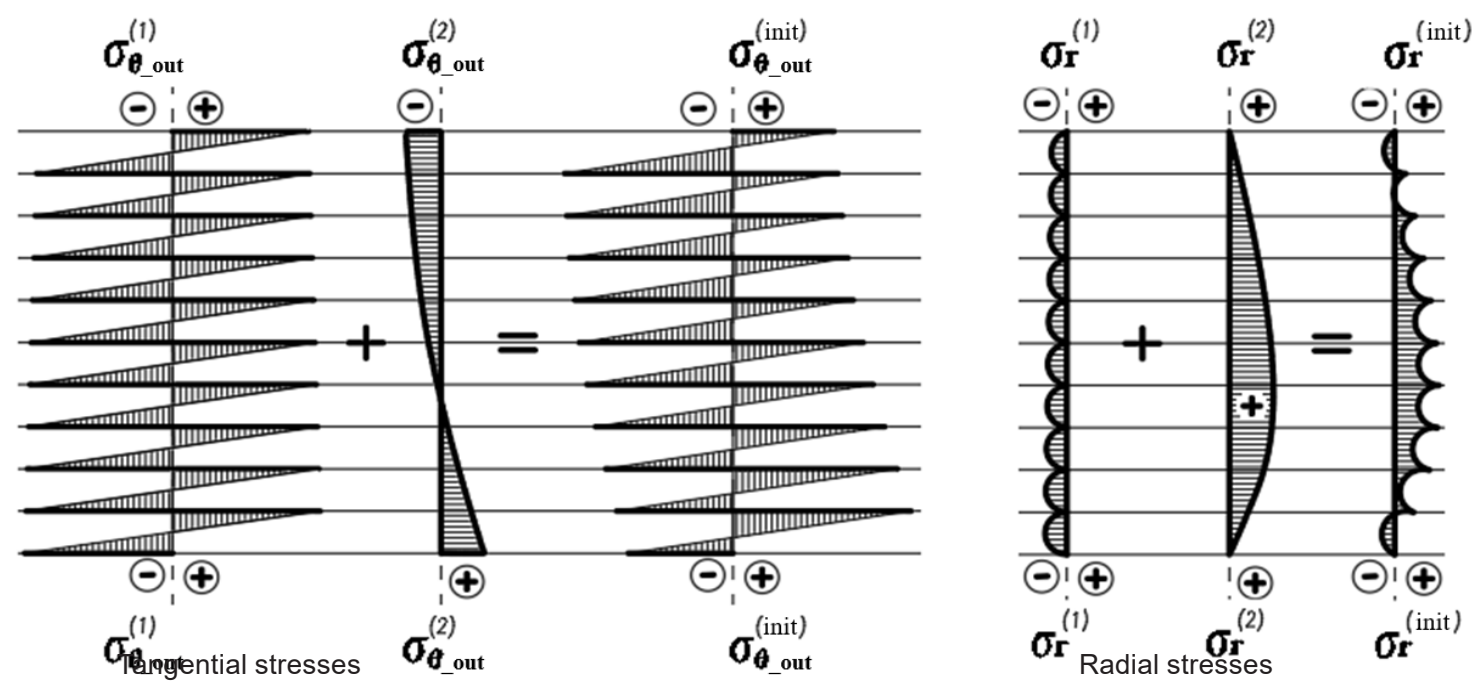

Figure 6. Cumulation of tangential and radial stresses at stages 1 and 2 of curved laminated beam production 
In summary, a curved laminated element always experiences initial radial tensile stresses across the timber fibers. Notably, they reach their maximum in the glue seams in the middle of the section. The maximum tangential stresses occur in specific glue seams within the package layers: tensile stresses $\sigma_{\theta \text { out }}^{\text {init }}$ occur on the convex side of plank 1 , compressive stresses $\sigma_{\theta}^{\text {init }}$ occur on the concave edge of plank $n$. The maximum shear stresses $\tau_{i}^{\text {init }}$ occur in the glue seams of the layers with minimum curvature radii, where the curved sections gradually transition into the straight sections. Apart from the glue seams, the shear stresses also occur in the lamellae layers themselves.

During the gluing process, each layer (aside from the faces of the outer lamellae) is dipped in glue, which also acts as a plasticizer. This results in plasticization, to a certain degree. For reference: the plasticization of timber fibers is a technique commonly used for making bentwood furniture. Some of the most commonly known plasticizers include urea, phenol formaldehyde resin, and other substances (Gorshin, 1979). On the one hand, this makes it easier to bend the lamellae and achieve the necessary curvature; on the other hand, this reduces the stresses in the layer's outer fibers (as deep as the glue reaches). This diminishes the force that is driving the curved laminated element to straighten out after the pressing-out stage. Thus,

$$
M_{p l}^{f}=k_{p l} \cdot k_{E} \cdot \frac{E \cdot b \cdot \delta^{2}}{12} \ln \left(1+\frac{n}{\beta_{1}}\right),
$$

where $k_{\mathrm{pl}}$ is the coefficient that accounts for the reduction of the elastic forces that straighten out the lamellae (caused by glue plasticization in the most stressed outer faces). We shall roughly assume that $k_{p l} \approx 0.8 \div 0.9$. This assumption may later be adjusted through experimentation. We can approach the plasticization effect as the reduction of the elasticity modulus at stage 1 of production.

We shall also assume that, once the glue hardens during stage 2 , the timber regains its elastic properties, while retaining its new strained state. Subsequently, after the curved laminated structure spends some time in storage, the inner stresses relax. Gordon (1973) obtains, for the purpose of simulating the relaxation process, approximate experimental values of the timber's elasticity modulus reduction coefficient $k_{E}$ (along the fibers), depending on the relative radius of the plank curvature $\beta_{i}$ and the time of the structure being held in a curved state. We shall adopt this coefficient for tangential stresses in the first approximation as $k_{E} \approx 0.9$. Furthermore, if we take into account the data from Regulation SP 64.13330.2017, cl. 6.10 and cl. 6.11, we can also depict the relaxation process as the reduction of the elasticity modulus by the $m_{l t . E} \approx 0.9$ long-term strength coefficient. In that case, we can formulate the following equations (Figs. 5 and 6 ) for the radial and tangential stresses after stage 2 (pressing out):

- maximum radial tensile stresses in the middle of the beam:

$$
\sigma_{r}^{(2)}=\frac{M^{f}}{4 \cdot \beta \cdot W}=\frac{1}{4 \cdot n} E \frac{\ln \left(1+\frac{n}{\beta_{1}}\right)}{2 \beta_{1}+n-1} .
$$

- tangential tensile stresses along the inner edge:

$$
\begin{gathered}
\sigma_{\theta_{-}{ }_{i n}=k_{E}}^{(2)} \cdot m_{l t, E} \cdot \frac{M^{f}}{W}\left(1+\frac{1}{2 \beta}\right)=k_{p l} \cdot k_{E} \cdot m_{l t, E} \\
\cdot \frac{E}{n^{2}}\left(\frac{1}{2}+\frac{1}{4 \beta}\right) \cdot \ln \left(1+\frac{n}{\beta_{1}}\right) .
\end{gathered}
$$

- tangential compressive stresses along the outer edge:

$$
\begin{gathered}
\sigma_{\theta_{-} \text {out }}^{(2)}=k_{E} \cdot m_{l t, E} \cdot \frac{M^{f}}{W}\left(1-\frac{1}{6 \beta}\right)= \\
k_{p l} \cdot k_{E} \cdot m_{l t, E} \cdot \frac{E}{n^{2}}\left(\frac{1}{2}-\frac{1}{12 \beta}\right) \cdot \ln \left(1+\frac{n}{\beta_{1}}\right) .
\end{gathered}
$$

Based on the dependencies that we found, we assessed the initial stress-strain state of the curved laminated element in the Mathcad-15 software, using the parameters that tend to occur frequently in a multi-layer curved laminated element.

For instance, given the data provided in Regulations SP 64.13330.2017, Table C.3, we obtain the following stage 1 data for pine lamellae with the design elasticity modulus along the timber fibers $E_{d}=E_{s} \cdot k_{p l} \cdot k_{E} \cdot m_{l t . E}=5.69 \mathrm{GPa}$, shear modulus along the fibers $G=0.35 \mathrm{GPa}$, layer number $n=10$, layer thickness $\delta=30 \mathrm{~mm}$, layer width $b=150 \mathrm{~mm}$, and the relative radius of the first lamella $\beta 1=200$ :
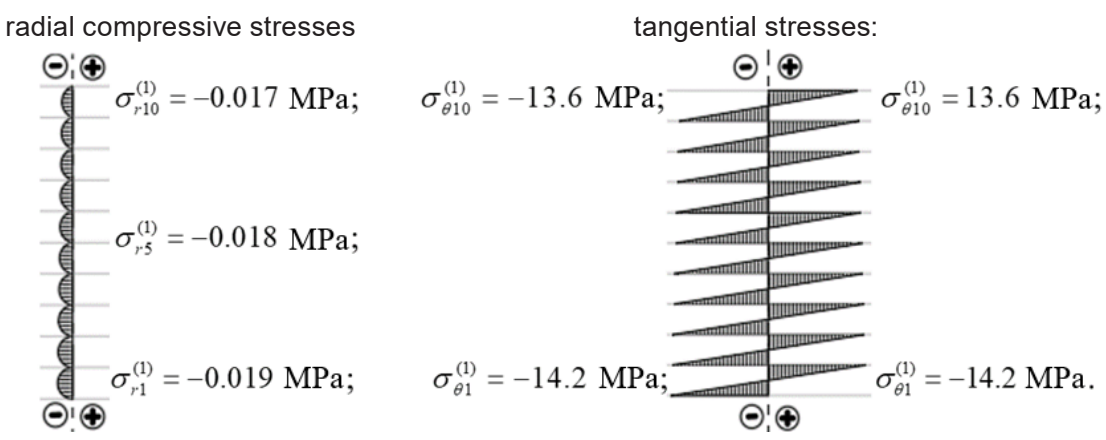

Figure 7. Numerical values of stresses during production stage 1 


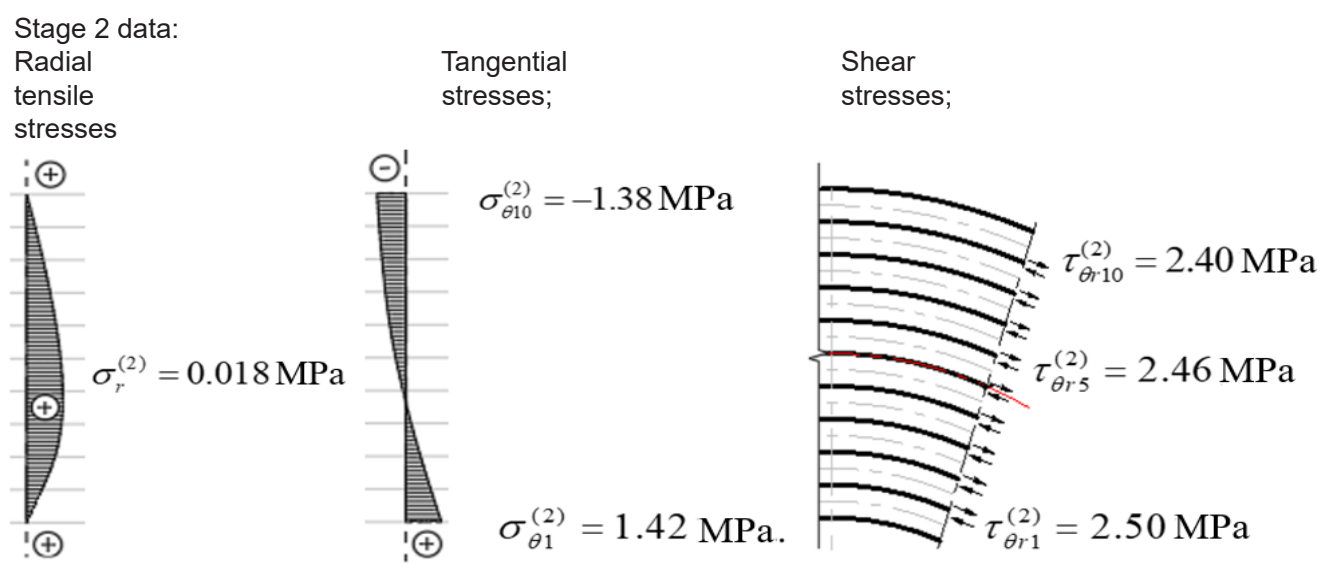

Figure 8. Numerical values of stresses during production stage 2

The total initial stress shall be as follows:

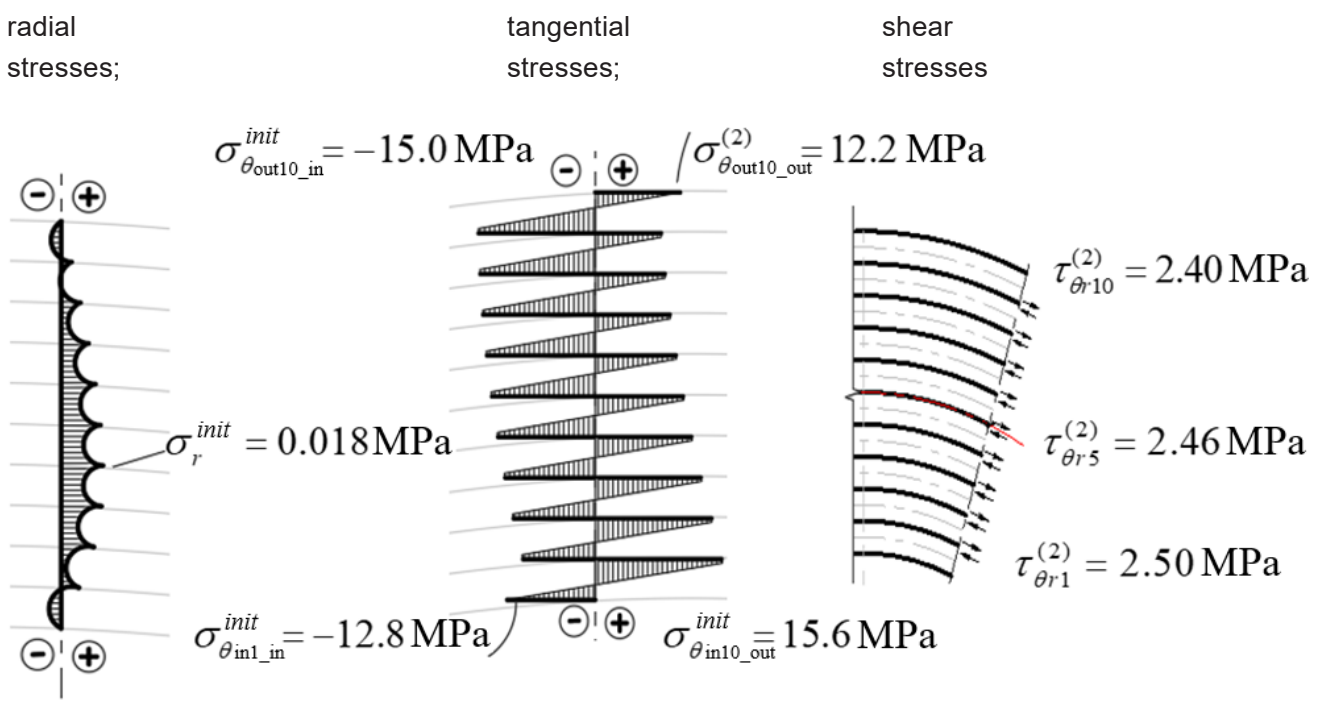

Figure 9. Total initial stress after pressing-out

The stress values shown in Figures 7, 8 and 9 approach the threshold of the respective values of design ultimate timber resistance. We must further note that the existence of tangential, radial, and shear stress also leads to the occurrence of "principal stresses", which affect the structure at a certain angle in relation to those timber fibers where the wood strength is significantly reduced. This fact is also overlooked in guidelines for analyzing curved laminated structures and merits further study.

\section{Results and Discussion}

In light of the above, we can conclude that the limit state of the curved laminated section of the wooden structure depends on the nature of stress that will cumulate with the initial stress during operation. This impact may cause different stress states within the curved section. Depending on the stress type and direction, the prestressed curved laminated element may be subjected both to straightening forces and bending forces that increase the curvature.

The aforementioned coefficients are recorded in Table 12 of Regulations SP 64.13330.2017, "Compression and Bending" and "Tension"; however, they only reflect the stress that is accompanied by the bending of curved sections. For instance, in the case of curved laminated cornice joints of threejoint articulated frames (Serov et al., 2011), where external load almost always creates a force that increases the section curvature, this coefficient is applied to tangential stresses. In this instance, the external load-related stresses along the outer and inner radii have the same direction as the initial stresses, and therefore both types add up. For radial stresses (in this case, stresses that are caused by external load and compress the element across the fibers), this coefficient is not needed, as the initial hazardous radial tensile stresses either decrease or convert into compression.

That said, if the curved segments of the laminated structures experience "straightening" forces, the nature of the stress-strain state changes entirely. In situations like this, the $m_{\text {bend }}$ coefficient provided in Regulations SP 64.13330.2017 is not applicable. Specifically, many well-known studies (American Wood Council, 2015; Maki and Kuenzi, 1965; Riberholt, 1979) show that in many boomerang-type 


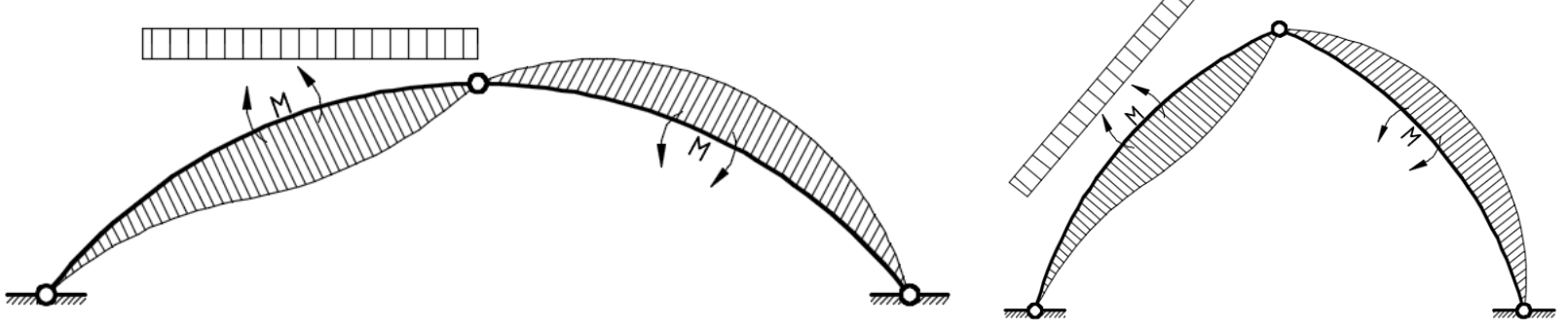

Figure 10. Bending moments that cause the straightening-out effect in the left semi-arches

curved laminated beams experiencing straightening forces, tangential stresses are opposite in sign to the initial tangential stresses, while the radial tensile stresses cumulate with the initial radial tensile stresses. In other words, the impact of tangential stresses on the structure's overall SSS decreases, while the role of radial tensile stresses across the fibers, by contrast, increases substantially. In this case, coefficient $m_{\text {bend }}$ must exceed 1.0 for tangential stresses and be less than 1.0 for radial stresses. However, there is no $m_{\text {bend }}$ coefficient for radial stresses across the timber fibers.

Another fact that is worth noting is the possibility of designing curved laminated beams with the convexity facing downward.

For such designs, the $m_{\text {bend }}$ coefficients must have other values, properly reflecting the resulting stress.

Aside from curved beams that are subjected to a transverse load force that straightens them out, construction practice often deals with compressed bent structures that experience "unbending" stress. For instance, such popular solutions as curved laminated arches with a depressed, pointed, or circular outline, tend to undergo compression (accompanied by bending) during operation. That said, multiple calculations show that when the structure is subjected to unilateral load (for instance, caused by the rain and/or snow), the normal compression force $N$ is accompanied by bending moments $M$, which straighten out (unbend) the curved laminated arches.

It is also interesting to note that, in situations like this, the stress from the normal compression force $\mathrm{N}$ amounts to less than $10-15 \%$ of the stress from bending moment $\mathrm{M}$. Thus, what we are left with are compressed bent curved elements that operate under an immense unbending force. But such a force always creates radial tensile stresses across the timber fibers. In (Schmidt, 1980), we observed that a test of compressed bent laminated elements with a large curvature radius was accompanied by destruction, caused by radial tensile stresses across the fibers. Such initial stress exists even in structures with a small curvature radius. And if it cumulates with the unbending force, the likelihood of destruction caused by tangential stresses decreases, while the likelihood of destruction caused by radial tensile stresses across the fibers increases. Furthermore, if such structures also have cracks due to loss of moisture, radial stresses are only going to make these cracks broader.

\section{Conclusions}

This preliminary study has rationalized the need for analyzing curved laminated wooden elements while using the rules that differ from those applicable to straight elements, accounting for the direction of the inner forces $M, N$ and $Q$, and for the prestress during production. 


\section{References}

American Institute of Timber Construction (2012). Timber construction manual. $6^{\text {th }}$ edition. Hoboken, NJ: John Wiley \& Sons, Inc.

American Wood Council (2015). National Design Specification for Wood Construction. 2015 Edition. [online] Available at: https://www.awc.org/pdf/codes-standards/publications/nds/AWC-NDS2015-ViewOnly-1603.pdf [Date accessed 15.06.2020]

British Standards Institution (2008). BS EN 1995-1-1:2004+A1:2008. Eurocode 5: Design of timber structures. Part 1-1: General - Common rules and rules for buildings.

British Standards Institution (2012). PD 6693-1-1:2012. Published Document -Recommendations for the design of timber structures to Eurocode 5: Design of timber structures Part 1-1: General - Common rules and rules for buildings.

Colling, F. (1986). Influence of volume and stress distribution on the shear strength and tensile strength perpendicular to grain. In: Proceedings of the CIB W18 Meeting, Florence, Italy. Paper 19-12-3.

Filin, A. P. (1978). Applied mechanics of deformable solids. 2. Moscow: Nauka, 616 p.

Foschi, R.O. (1971). Stresses in curved glued-laminated timber beams: experimental study. Forest Products Journal, 21 (7), pp. 42-48.

Gordon, E. Ya. (1973). Impact of initial bending stress on the behavior of curved laminated structures under bending compression. Author's abstract of PhD Thesis in Engineering. Moscow: Kuibyshev Moscow Institute of Civil Engineering.

Gorshin, S. N. (ed.) (1979). Wood handbook. US Forest Products Laboratory. Moscow: Lesnaya Promyshlennost (Forest Industry), $544 \mathrm{p}$.

Kucherenko Central Research Institute for Structural Construction (1986). Guidelines on designing wooden structures (supplement to Construction Rules and Regulations SNiP II-25-80). Moscow: Stroyizdat, 216 p.

Larsen, H. J. (1986). Eurocode 5 and CTB structural timber design code. In: Proceedings of the CIB W18 Meeting, Florence, Italy. Paper 19-102-2.

Lekhnitsky, S. G. (1977). Theory of anisotropic body elasticity. $2^{\text {nd }}$ edition. Moscow: Nauka, Main Editorial Office for Literature on Physics and Mathematics, $416 \mathrm{p}$.

Maki, A. C. and Kuenzi, E. W. (1965). Deflection and stresses of tapered wood beams. Madison, WI: U.S. Department of Agriculture, Forest Service, Forest Products Laboratory.

Ministry of Construction, Housing and Utilities of the Russian Federation (2017). Regulations SP 64.13330.2017. Timber structures. Revised edition of SNiP II-25-80 (Construction Rules and Regulations). Moscow: Standartinform, 97 p.

NSAI (2013). EN 14080:2013. Timber Structures - Glued laminated timber and glued solid timber.

Riberholt, H. (1979). Tapered timber beams. In: Proceedings of the CIB W18 Meeting. Paper W18/11-10-1.

Schmidt, A. B. (1980). A study of highly curved sections' behavior in laminated wooden structures. Author's abstract of PhD Thesis in Engineering. Leningrad: Leningrad Civil Engineering Institute.

Serov, Ye. N., Sannikov, Yu. D. and Serov, A. Ye. (2011). Wooden structure design: study guide. Moscow: ASV Publishing House, $536 \mathrm{p}$. 


\title{
НАПРЯЖЕННО-ДЕФОРМИРОВАННОЕ СОСТЯНИЕ ДЕРЕВЯННЫХ ГНУТОКЛЕЕНЫХ ЭЛЕМЕНТОВ ПРИ ИЗГОТОВЛЕНИИ
}

\author{
Александр Борисович Шмидт \\ Санкт-Петербургский государственный архитектурно-строительный университет \\ 2-ая Красноармейская ул., 4, Санкт-Петербург, Россия \\ E-mail: shmidt.a.b@lan.spbgasu.ru
}

\begin{abstract}
Аннотация
Напряженно-деформированное состояние (НДС) деревянных гнутоклееных элементов может значительно отличаться от НДС прямолинейных клееных деревянных элементов не только по степени кривизны, но также и по параметрам изготовления и направления действующих нагрузок при эксплуатации. При изготовлении криволинейного элемента путем склеивания изогнутых досок (ламелей) конструкция приобретает внутренние начальные напряжения, вызванные стремлением отдельных гнутых ламелей вернуться в прямолинейное состояние. После изготовления в элементе возникает неравномерное начальное напряжённое состояние, которое изменяет его прочностные свойства в различных структурных направлениях по отношению к волокнам древесины. В дальнейшем это влияет на напряжённое состояние конструкции от действующих внешних нагрузок. Этот фракт остается не вполне освещенным в российских и зарубежных нормах (CП, EuroCode 5, DIN) и явился предметом исследований автора. Методы: С этой целью рассматривается математическая модель процесса формирования НДС гнутоклееных деревянных элементов, который условно разбит на две стадии: 1-ую - гнутья отдельных ламелей, их склеивания и запрессовки, 2-ую - распрессовки гнутоклееного пакета. Так создается начальное преднапряжение в виде комбинации тангенциальных, радиальных и касательных напряжений. Результаты: Получена графическая картина суммарного преднапряженного состояния на 1-й и 2-й стадиях, которая позволяет прогнозировать напряженное состояние гнутоклеёных деревянных конструкций при переменных эксплуатационных нагрузках. Обсуждение: Указывается на влияние процессов релаксации начальных напряжений, которые следует дополнительно исследовать. В зависимости от направления и величины эксплуатационных нагрузок гнутоклееный участок конструкции может «разгибаться» с уменьшением кривизны или наоборот далее «сгибаться» с ее увеличением. Это не вполне корректно учитывается в нормах проектирования деревянных конструкций и требует изучения.
\end{abstract}

\section{Ключевые слова}

Гнутоклееный деревянных элемент, процесс изготовления криволинейных деревянных конструкций, начальное преднапряженное состояние, сочетание начального преднапряжения с напряжениями от эксплуатационных нагрузок. 